\title{
"Sou da fronteira": narrativas orais e dinâmicas identitárias entre Argentina, Brasil e Uruguai
}

\section{Luciana Hartmann}

\section{(2) OpenEdition \\ 12 Journals}

Edição electrónica

URL: http://journals.openedition.org/aa/1052

DOI: $10.4000 /$ aa. 1052

ISSN: 2357-738X

Editora

Programa de Pós-Graduação em Antropologia Social (UnB)

\section{Edição impressa}

Data de publição: 1 dezembro 2011

Paginação: 187-213

ISSN: 0102-4302

\section{Refêrencia eletrónica}

Luciana Hartmann, «"Sou da fronteira”: narrativas orais e dinâmicas identitárias entre Argentina, Brasil e Uruguai», Anuário Antropológico [Online], v.36 n.1 | 2011, posto online no dia 17 novembro 2015, consultado o 28 abril 2021. URL: http://journals.openedition.org/aa/1052 ; DOI: https://doi.org/ 10.4000/aa. 1052

\section{(c) (i) $९$}

Anuário Antropológico is licensed under a Creative Commons Atribuição-Uso Não-Comercial-Proibição de realização de Obras Derivadas 4.0 International. 


\title{
"Sou da fronteira": narrativas orais e dinâmicas identitárias entre Argentina, Brasil e Uruguai
}

\author{
Luciana Hartmann \\ Programa de Pós-Graduação em Arte/UnB
}

Eu sou da fronteira, nasci e me criei na fronteira.

(Dona Nair, 69 anos - Cerro Pelado, Uruguai)

Cultura da fronteira ou fronteiras da cultura? De que fronteira, afinal, estamos tratando ? $^{1}$ Respondo não respondendo propriamente, mas esboçando um pouco da paisagem semântica que acolhe o conceito de fronteira neste artigo. Fronteiras geopolíticas: Argentina, Brasil, Uruguai. Fronteiras narrativas: causos, cuentos, anedotas, histórias de vida. Fronteiras do imaginário: lobisomens, bruxas, luz mala, histórias de contrabando, histórias de guerra. Fronteiras etárias: crianças, jovens, idosos... contadores de histórias. São estas fronteiras e as narrativas ${ }^{2}$ que as criam e as transcendem o foco principal deste artigo.

A abordagem ampliada do conceito de fronteira permite que os vários "lados" da questão sejam contemplados. Fronteira, considerada de forma abrangente e plural, é assim tomada como um conceito-chave para a tentativa de compreensão das relações sociais locais. Pincelando o texto com discussões teóricas que envolvem o conceito, pretendo demonstrar na prática, ou seja, a partir de dados etnográficos depreendidos das narrativas e dos discursos ouvidos nesta região, como a realidade fronteiriça e o imaginário relativo a ela são vivenciados. ${ }^{3}$

Ainda que pouco valorizadas pela população local, há diversas particularidades que afloram das/nas práticas culturais dos habitantes desta região de fronteira que são evidentes para quem é de fora. Desde seus costumes, seu falar, o trânsito entre "o lado de cá" e o de lá, as relações pessoais, as ocupações, o lazer, o comércio, tudo parece ser permeado por um modo de ser fronteiriço, que será evidenciado no texto por uma seleção de discursos identitários que emergiram durante a pesquisa etnográfica (em situações de conversa - ou charla - já que não utilizo entrevistas formais). ${ }^{4}$

\section{Rabiscos teóricos: definindo "fronteira"}

O problema da fronteira parece estar ligado à questão fundante da antropologia: a cultura e suas delimitações. Para Donnan e Wilson (1999:9), embora os an- 
tropólogos frequentemente assumam que culturas locais são elementos parciais de culturas mais abrangentes, eles também tratam muitas vezes essas culturas como objetos concretos, que estariam limitados por fronteiras em geral condizentes com limites territoriais. Grimson (2000), ao fazer uma revisão da utilização do conceito de fronteira ao longo da história da antropologia, tanto no sentido concreto (ligado à territorialidade) quanto no sentido simbólico (como nos ritos de passagem, por exemplo), também indica a preeminência, durante longo tempo, dos estudos de pequenos grupos separados, como se cada grupo tivesse "uma cultura" em si mesmo.

Em certa medida, nesta perspectiva, as noções de território e cultura coadunavam-se e as fronteiras de um indicavam as fronteiras do outro. Grimson aponta, entretanto, para a mudança ocorrida nesta tendência desde o fim dos anos 70, quando uma série de trabalhos antropológicos passou a se dedicar ao estudo das experiências pessoais e dos imaginários coletivos na fronteira, desafiando as visões que coadunavam os limites políticos com os limites culturais.

No Brasil, os trabalhos de Darcy Ribeiro e de Roberto Cardoso de Oliveira com populações indígenas foram antecessores dos estudos sobre fronteira. Neles, buscava-se considerar as relações no "interior do contato interétnico". Já os estudos relativos ao campesinato - representados, num primeiro momento, por Otávio Velho (1972; 1976), na antropologia, e por José de Souza Martins (1997), na sociologia, deslocaram o eixo da discussão da situação de contato entre sociedades distintas (nacional e indígenas) para retomar a diversidade nacional em si mesma. A temática do desenvolvimento é outro fator sempre presente nas discussões sobre fronteira. Vale lembrar aqui a tese, apresentada em 1893 por Frederick Jackson Turner considerado o mais importante teórico e historiador da fronteira norte-americana - que relaciona o desenvolvimento do Estado-nação à exploração da fronteira. ${ }^{5}$

Na década de 80 a discussão sobre a fronteira ressurge transformada. De acordo com Cláudia Fonseca, em apresentação à coletânea Fronteiras da Cultura (1993), a partir de então a questão dos territórios e das identidades, que só parecia relevante quando ligada ao Estado-nação, assume novas feições. Segundo a autora (1993:5): "Revelou-se a importância do estudo de microterritórios, de regionalismos, de identidades em nível de microgrupos para a compreensão da realidade política e econômica do mundo moderno".

Ao longo de minha etnografia, pude perceber que, na fronteira estudada, territórios, sociedades, identidades (e os discursos/narrativas sobre estes) transcendem seus Estados-nação de origem e que a microrregião em questão, localizada "entre" estes Estados, tem na (cultura da) fronteira seu eixo comum. Laballe (1996:17), em estudo feito entre Argentina e Brasil, atentou para esta característica dos ha- 
bitantes da fronteira: “Eles estão 'entre', em 'terra de ninguém’”. Também pude verificar a referência da fronteira como "terra de ninguém” em diversas narrativas que tratam, por exemplo, de assassinatos cometidos na região, cujos corpos são abandonados "na linha", pois esta seria uma "terra sem dono", onde os poderes dos Estados não teriam ingerência.

A partir desse pressuposto, a noção de fronteira que permeará minha análise será inspirada na de front, sofrendo influência direta dos trabalhos desenvolvidos por Jacques Leenhardt $(2001,2002)$ sobre esta região de tangência entre Argentina, Brasil e Uruguai. Ao definir a fronteira como local privilegiado de conflitos e tensões, o autor posiciona-a também como um campo fértil de contatos e de negociações. Da mesma forma percebe Don Chachá, de 75 anos, diretor de escola rural, aposentado e morador de Rivera/UY, a quem recorro para introduzir as falas diretas dos habitantes da fronteira: "El espirito guerrero praticamente fue eso: fronteras, fronteras".

A imagem que Bastide (1980:178) constrói da região também contribui para reforçar esta ideia do "ethos guerreiro" dos habitantes da fronteira, desenvolvido em concomitância às relações de integração entre os "lados":

Fronteira é local de luta, mas é também local de interpenetração, de trocas de civilizações, principalmente quando é móvel. A que separa as possessões espanholas das possessões portuguesas deslocava-se ao sabor dos golpes de surpresa e das batalhas; era fronteira feita de corpos humanos e não de montanhas ou de rios. Descendentes de velhas famílias portuguesas são encontrados no Uruguai, descendentes de velhas famílias espanholas são encontrados no Rio Grande do Sul. Os indivíduos misturaram-se numa área movediça que não era possessão de nenhuma coroa, e sim o domínio de rebanhos e de capinzais.

Ainda pertinente à abordagem aqui proposta é a afirmação de J. Leenhardt de que "a fronteira é menos uma linha do que um espaço" (2001:19), já que sua noção correlacionada, limite, tem origem na palavra latina limes, que designa um intervalo, uma margem, uma borda sem apropriação. ${ }^{6}$

Esse "espaço fronteiriço", no qual a população local convive e se comunica através de variadas formas de oralidade, foi profundamente vivenciado durante minha pesquisa etnográfica, sugerindo o que passei a tratar por "cultura da fronteira”. Embora essa hipótese tenha sido levantada antes de minha chegada efetiva em campo, a noção de que há uma "cultura da fronteira" ligando as comunidades vizinhas dos três países em questão confirmou-se na observação dos relacionamentos "intrafronteiriços" "que criam uma identidade comum, e na escuta de narrativas 
e discursos que evidenciam que a população também se vê e se autoidentifica a partir desta base comum - a experiência de viver na fronteira (Hartmann, 2006). A noção de "cultura da fronteira", é importante salientar, relaciona-se à ideia de que grande parte da população local participa da mesma comunidade narrativa, definida pelo conhecimento mútuo de narrativas e pelo hábito de compartilhá-las, numa unidade interdependente e dinâmica (Lima, 1985).

A observação de Don Jorge, comerciante de 60 anos, de Paso de Los Libres (AR), ajuda a vislumbrar esta questão: "Claro, eso en toda la frontera, ya las costumbres del hombre de frontera son distintas de las costumbres de otros lugares, no?”. Pedro Riera, 50 anos - diretor de um liceu rural em Rivera (UY) - também faz um comentário neste sentido: "La frontera es una tierra de oportunistas, es una tierra más cosmopolita, con más variedad, hay asientamientos de coletividades que no se dán en otros lugares...". A noção de fronteira ("la frontera”), como se pode perceber, contribui na construção dos múltiplos discursos identitários da população. Desta forma, as identidades nacionais dos três países manifestam-se paralelamente àquilo que estou chamando de "identidade fronteiriça", como veremos com maior detalhe adiante. ${ }^{8}$

Ainda que haja um espaço de convivência comum, com códigos compartilhados, cujos limites diferem daqueles instituídos politicamente, é inegável que a presença de uma "linha" demarcatória, que divide este espaço, permaneça muito forte. É por este motivo que concomitantemente às alusões ao "nós da fronteira" sigam-se comentários sobre "atravessar a linha":

Depois fiz casa, fiz galpão... arrumei com a comissão de límite uma área de campo que dava prá nós tá bem, fiz horta, potreiro pra cavalo, ajeitei, ficou bem bonitinha ela. Bolichinho... verdadeiro. Duas portas, uma em frente à outra, uma no Brasil e outra no Uruguai, a casa beeem na beira da linha, beeem no límite, bastante espaço... (Barreto - Santana do Livramento, BR). ${ }^{9}$

Ou também, expressão ainda mais frequente, ir para o "outro lado”:

Naquele tempo se levou muito cavalo pro outro lado (Don Martimiano, 80 anos, tropeiro aposentado - Cerro Pelado, UY).

Eu tenho uns parentes aí do outro lado - ali em Bella Unión - bem defronte à ponte tem uma irmã da minha mulher (Seu Darci, 82 anos, tropeiro aposentado - Barra do Quaraí, BR).

Não obstante a presença da "linha" (que, mesmo invisível, no caso da fronteira 
seca, é sempre lembrada), uma ponte ou um marco de limites, de um lado e de outro, acredito que as sociedades em questão constituem-se, igualmente, como "sociedades de fronteira". O conceito de limite só adquire sentido quando integrado a outros, como divisa, demarcação e, no caso deste trabalho, os de território e territorialidade. Embora possa existir um nexo entre identidade e territorialidade, a identidade é, antes de tudo, uma relação social. Fala-se em um "apagamento da territorialidade" (Mesquita, 1994), que existiria nos grandes centros urbanos e também nas áreas de fronteira. Da mesma forma, observa-se que a comunidade narrativa aqui abordada, pelo intenso contato praticado entre um lado e outro, desenvolve sua identidade não a partir da ideia de território nacional mas, ao contrário, pela noção de pertencimento à fronteira.

O "estado de cultura" da fronteira (Leenhardt, 2001), que confere características peculiares a essas sociedades que convivem de forma ambígua com a diferença - ora em conflito, ora em comunhão, ora "eles", ora "nós" - é tratado neste artigo a partir de falas, depoimentos, opiniões dos seus habitantes que, através desses discursos, organizam sua experiência de viver na fronteira.

\section{Que fronteira é essa?}

A população que habita a zona de fronteira entre Argentina, Brasil e Uruguai, devido à sua formação cultural semelhante e ao seu contato frequente, possui, em muitos sentidos, memória e referenciais cotidianos comuns. Unidos, por um lado, pelas características geográficas da região - o Pampa ${ }^{10}$ - e por uma formação histórica e uma organização social similares, os habitantes da região, por outro lado, encontraram-se muitas vezes lutando em frentes opostas em conflitos que tiveram como consequência o estabelecimento das fronteiras políticas entre os três países.

A problemática da fronteira, inclusive pela intensidade histórica do contato nesta região, vem acompanhada de um discurso paradoxal que tende ora para afirmar a diferença - nesses momentos as tensões agravam-se e os conflitos tornam-se inevitáveis - ora para comemorar suas semelhanças - quando a integração se torna uma realidade. A fronteira é então o espaço onde o paradoxo entre ser igual ou ser "outro" mostra seus contornos mais definidos.

A proposição de Donnan e Wilson (1999:12) - de que há culturas da fronteira (border cultures), maneiras de viver e formas de significar que são partilhadas somente ou principalmente pelos povos fronteiriços, pertencentes a qualquer um dos lados da demarcação legal do Estado - vem ao encontro do que venho argumentando.

Essa relação ambígua, de conflito ${ }^{11}$ e de integração, presente já na fundação da cultura desta fronteira é, portanto, uma abordagem central para uma reflexão so- 
bre o tema. Como observa Grimson (2000:23), o estudo da fronteira em si desafia qualquer noção estática, uniforme e não relacional de cultura e de identidade, pois deveria incorporar à sua perspectiva analítica não somente a "mescla cultural", mas também a aliança e os conflitos sociais e políticos inerentes à condição de viver na fronteira.

$\mathrm{Na}$ perspectiva das microrrelações, os conflitos ocupam uma importância relevante na vida social da região, deixando de opor países e suas economias para opor patrões e empregados, trabalhadores urbanos e rurais, jovens e idosos, homens e mulheres, tradição e modernidade, humanos e animais, natureza e sobrenatureza... ${ }^{12}$ Ou seja, a identidade, entre os pequenos grupos sociais, "intrafronteiriços", encontra-se também, e sobretudo, na própria convivência, manipulação, interpretação e, em alguns casos, "ficcionalização" (Palleiro, 1992:17-18) de suas experiências situadas de conflito. Diferentemente do que procuro defender, entretanto, Grimson (2000:18) considera que a convivência cotidiana em uma zona fronteiriça não se traduz necessariamente, para a população local, em uma "identidade fronteiriça”. Para ele, a própria dinâmica de interação cotidiana gera, em muitos casos, um crescimento dos atritos e dos conflitos. Como venho afirmando, porém, na região aqui enfocada, parte da identidade fronteiriça relaciona-se exatamente com o fato de a população compartilhar as mesmas experiências de violência e conflito, e as respectivas narrativas sobre eles.

Cabem nesse momento algumas considerações: como venho desenvolvendo, há uma identidade comum que une os grupos fronteiriços e que pode ser especialmente percebida através das narrativas orais. Esta identidade fronteiriça, no entanto, não supõe um obscurecimento absoluto das identidades nacionais dos habitantes dos países em questão. Pelo contrário, tanto a literatura quanto o material etnográfico demonstram que se estabelecem aí relações de simultaneidade, em que várias identidades convivem e se alternam conforme o contexto. ${ }^{13}$

Como vimos, a maior parte da linha que separa Brasil e Uruguai se constitui por uma "fronteira seca", o que confere características especiais à região, principalmente no que diz respeito ao acesso facilitado de um país para outro. O pequeno número de aduanas de imigração, sua limitada atuação na linha divisória e a incipiente demarcação feita com marcos de concreto permitem o trânsito livre na maior parte da região, gerando na população uma sensação de domínio e de pertencimento a ambos os "lados". Este tipo de situação leva a uma intensificação evidente, nos mais diversos níveis, das relações interpessoais, "intrafronteiriças" que, no entanto, nem sempre são ratificadas pelas máquinas burocráticas dos respectivos países. Como explica Pedro Riera, de Rivera/UY: 
Yo tengo bien claro el concepto de soberanía, derechos humanos. Pero explicar a un hombre que vive en una frontera que ciertas cosas no pueden ser, más allá de una calle... [ele ri] No! No te entienden. No siguen ni a líderes, ni a caudillos ni a nadie! Él no se ata a leyes. [...] [troca de idioma] E quem explica pra eles donde começa e donde termina? Não tem. Eles vão pra um lado, vão pro outro e não tem problema.

Já a outra fronteira em questão, entre Argentina e Brasil (Paso de Los Libres e Uruguaiana), possui características bem diferentes, marcadas pelo acidente geográfico que delimita os domínios de um e outro país, o rio Uruguai. A existência de uma ponte que liga os dois países, ao invés de aproximá-los, possibilitou o posicionamento estratégico de mecanismos de controle estatais dos quais não é possível fugir: "Todo nos une, el puente nos separa", foi o que ouvi de um argentino, num grupo que falava justamente sobre as relações entre as populações vizinhas. No entanto, algumas questões que aparecem em zonas fronteiriças devem ser tomadas com precaução, lembra Grimson (2000:29), como o discurso nativo de que "a fronteira não existe" ou "estamos integrados desde sempre". Segundo ele: "A pesar de lo que dicen los actores, es posible que la frontera no exista para algunas cosas y sí exista para otras". E um dos fatores de identificação da população intrafronteiriça seria o seu posicionamento como zona periférica e marginalizada em relação às suas respectivas metrópoles nacionais. O tema da fronteira como periferia também é problematizado por M. H. Martins (2002:235) que, ao traçar uma relação entre fronteira e margem, aponta para esta última como possibilidade de distanciamento da legalidade, pois periferia e fronteira estariam fadadas a compartilhar desditas, desvantagens. Devido à sua condição de marginalidade, as populações nessa situação tenderiam a usufruir de uma liberdade impossível para aquelas próximas da "lei e da ordem".

Seu Santos Reis, pedreiro de Uruguaiana, também comenta que com a construção da ponte, inaugurada em 1946, as relações entre as duas cidades modificaram-se bastante. Seu pai, que trabalhava como barqueiro levando mercadorias para um lado e outro, acabou sendo preso, pois o policiamento e a repressão ao contrabando foram intensificados:

Porque era permitido [trazer mercadorias], mas não tanta quantidade quanto 0 pessoal trazia de barco, né? Porque eles tratavam 2 mil quilos, 5 mil quilos, tinha que trazer, né? Era assim que era. Enquanto na ponte permitiam 100 quilos pra uma pessoa, uma bolsa de farinha. Então, a pessoa quantas vezes tinha que ir lá buscar 100 quilos de farinha? É verdade que passava umas quantas vezes, né? Pas- 
savam... A pessoa ia lá e trazia 10 quilos, depois ia lá e trazia mais 10 quilos, mas era assim. E ele [seu pai] perdeu tudo assim. E depois ele foi fazer um trabalho com um barco emprestado, um barco do patrão, foi a vez que pegaram ele, a Marinha brasileira pegou ele e prenderam aqui. Aí ele tirou um ano de cadeia.

Minha própria inserção no campo foi marcada por esses diferenciais entre uma fronteira e outra. Para o Uruguai (divisas entre Santana do Livramento, BR-Rivera, UY; Quaraí, BR-Artigas, UY; Serrilhada, BR-Cerrillada, UY) ${ }^{14}$ sempre tive acesso direto, mesmo para o interior do país onde, ainda que passasse por aduanas, nunca me pediam documentos e dificilmente tinha o carro revistado.

Já na Argentina (divisa entre Uruguaiana, BR-Paso de Los Libres, AR), cada entrada no país significava o dispêndio de algum tempo, que variava conforme o dia da semana (devido às regras vigentes naquela época para o comércio entre os países). Se eu fosse somente até Paso de Los Libres, não precisava de visto de entrada, mas aguardava igualmente na fila e tinha o carro revistado, tanto na ida quanto na volta. Para ir até Tapebicuá ou Mercedes, distantes, respectivamente, 40 e 120 quilômetros da fronteira, precisava registrar todo o equipamento, preencher uma ficha do Serviço de Migración e solicitar permanência no país para dias específicos. Ou seja, não poderia permanecer mais, caso quisesse ou precisasse, assim como não podia fazer idas e vindas rápidas ou sem planejamento. Essa forma de controle, através da dupla vigilância, direta e indireta (tarifas alfandegárias e guardas de fronteira, mais a coordenação centralizada dos passaportes), seria, de acordo com Giddens (1994:34), um dos distintivos do Estado-nação.

Uma pequena narrativa permite compreender melhor as implicações deste sistema burocrático de controle nas relações sociais entre os vizinhos da fronteira:

Otro día me encuentro con un intimo amigo mío de Uruguayana que hacia tiempo que no me venia ver.Y bueno, digo: "Chê, hace mucho que no venés a mi casa, qué sé yo..." - "Pero que querés que yo va a tu casa si tengo que pasar esa aduana de miércoles [sic] ahí? Tengo que tardar una hora para que me manuseen, me pidan esto y me pidan el otro, y una base acá, la otra allá, parece que estuviéramos en guerra...". Y es verdad, es lamentable porque es la verdad ${ }^{15}$ (Don Jorge, 60 anos, comerciante - Paso de Los Libres, AR).

Embora viajando sozinha nunca tenha tido problemas, a polícia argentina também se mostrou mais difícil de lidar: num episódio, o policial de um posto, já na autoestrada, a 20 quilômetros da fronteira, quis me extorquir dinheiro; em outra ocasião, um policial da aduana não queria liberar minha passagem sem que eu fornecesse meu número de telefone celular, pois queria que marcássemos um encontro... 


\section{Relações intrafronteiriças}

Talvez uma das estratégias mais ricas para se analisar a "cultura da fronteira" da região em questão seja através das relações estabelecidas entre seus habitantes. Uma exposição destas relações, a partir de dados etnográficos, especialmente oriundos de observação e de discursos e narrativas orais locais, permitirá que se vislumbre a dinâmica com que atuam essas sociedades "intrafronteiriças".

\section{Comércio (contrabando)}

Possivelmente uma das maiores fontes de contato entre a população da região da fronteira, e que melhor caracteriza as zonas fronteiriças, seja o contrabando. A historiadora Vera Albornoz (2000), ao analisar esta prática na região, consideraa, como procuro igualmente fazer, como um aspecto importante no processo de integração entre os sujeitos da fronteira, uma relação de encontro e aproximação.

Esta forma de comércio, ilegal perante o Estado, mas perfeitamente legítimo para os habitantes da fronteira, está inserido de tal forma, tanto historicamente quanto na sua vida cotidiana, que uma senhora uruguaia chegou a me dizer: "si el diablo viniera a buscar los contrabandistas de Rivera, nos tendria que llevar a todos". Seu comentário acompanhava a discussão instaurada na cidade naquele momento (agosto de 2000) relativa à prisão de um grupo significativo de pessoas - advogados, comerciantes e policiais aduaneiros - responsáveis pela movimentação de uma rede que permitia a passagem ilegal de centenas de caminhões com produtos oriundos do Brasil para o Uruguai. Apesar da grandeza da corporação revelada e da consciência de que esta forma de atuação representava um crime, o fato de que toda a população pratica diariamente pequenos contrabandos justificava também, de certa forma, a existência de redes mais portentosas de comércio ilegal entre os países. Outro fator que torna simpáticos os “contraventores” é que estes, em se tratando das pequenas cidades da região, em geral são pessoas próximas, membros da família ou do grupo de amigos. ${ }^{16}$

O enriquecimento e a decadência das famílias e o desenvolvimento das próprias cidades da fronteira sempre tiveram relação com o contrabando. Segundo Gaúcho Barreto, de Livramento (que chegou a ficar preso dez anos porque não aceitava pagar a coima - propina - aos policiais de um lado e de outro): "Por isso que se diz fronteira, Luciana, onde for fronteira sempre tem contrabando, seje comprando ou vendendo, seje roubando...”. O Frigorífico Armour, por exemplo, instalado em Livramento em 1917, trouxe um inusitado progresso para as vizinhas Livramento e Rivera. Como era comum que os fornecedores do frigorífico possuíssem estâncias tanto no Uruguai quanto no Brasil, o contrabando era facilitado e o gado trazido do país vizinho chegava ao Brasil com a documentação "legal": "No departamento de 
Rivera o latifúndio de produção pecuária está intimamente vinculado às atividades do contrabando. Aqui a pecuária e o contrabando são duas atividades que se estimulam mutuamente" (Olyntho Simões apud Albornoz, 2000:113).

Pedro Riera, de Rivera (UY), também comenta sobre esta forma e a consequência deste tipo de contrabando:

Todas las familias económicamente fuertes de todas las ciudades de frontera, no hace muchos años atrás, en el contrabando originaran su patrimonio. Era época en que tenían campo de un lado e de otro. Abría la portera de un lado y se pasaba el ganado, depende de como convenía. Algo muy cómico fue... en el año 90 las ovejas riverenses tuvieran un talento único en todo el mundo, en todo el universo, porque podrían dar cuatro veces más lana de lo que es el promedio.

Estes grandes contrabandos, realizados por empresas e estancieiros, hoje em dia não são mais tão representativos devido à decadência da indústria frigorífica da região (o Armour fechou suas portas em 1996). ${ }^{17}$ E quanto aos pequenos contrabandos, realizados cotidianamente, até os dias de hoje?

Assim como nas aglomerações urbanas, as pequenas comunidades rurais da fronteira sempre se caracterizaram por sua "cultura de contrabando" (Aguiar, 2002:67), dependente desta forma de comércio. São comuns na região os narradores que contam sobre os pequenos contrabandos feitos de carreta, de um lado para o outro, atravessando campos e por vezes tendo que se embrenhar no mato para escapar da polícia. Os produtos trazidos nesses carregamentos serviam para abastecer os bolichos da zona rural. Há também muitas narrativas que tratam do enriquecimento de "bolicheiros" que se tornaram proprietários de estâncias, já que as dívidas contraídas com os fregueses eram cobradas com juros altíssimos e, em geral, pagas com parte da produção destes ou mesmo com frações de suas terras.

Escutei também diversas narrativas daqueles que faziam o abastecimento dos armazéns, os únicos que corriam riscos reais com a realização do contrabando, como Dona Iracema, de 77 anos, de Cerro Pelado (UY):

Yo fui contrabandista cuatro años. Venia de allá de Cerro Pelado hasta la Villa Indarte. Lejíssimos. Trahía cuero, lana, de contrabando. Llevaba el carro [carreta de bois] cargado. Claro, en ese tiempo todo era más barato [no Brasil], viste? Y mi compañero, que era el mayor, era el Chango [seu filho mais velho]. Pero pasábamos mal en el camino, te juro! Trueno, tormenta, agua... Y dentrávamos en las zanjas con l'agua en el pecho del caballo, nos mojábamos todos. La lucha fue grande. Para mi la lucha fue grande, grande. [muda de idioma] Eu contrabandeava por dentro dos campos, quer dizer, não era contrabando, eu ia buscar pros boliche ali, viste? 
Com informação retirada do jornal O Canabarro, de Livramento, de 1891, Bleil de Souza (1994:87) observa que eram principalmente as mulheres que carregavam as mercadorias desse comércio clandestino: "no meio das verduras transportadas pelas mulheres, habilmente escondidos, 'presos à cintura pela parte interna das saias, em bolsos falsos', vinham para o Brasil todos os artigos que essas mulheres conseguiam transportar". Vendidas as mercadorias que traziam, as mesmas mulheres voltavam às suas cidades carregando produtos brasileiros, como fumo, açúcar, café, erva-mate, álcool etc. ${ }^{18}$

Há também narrativas referentes ao contrabando feito através do rio Uruguai, entre Argentina e Brasil, de barco, como conta Seu Santos Reis a respeito do seu pai:

Então essa época eu me lembro. Ele trabalhou na parte da Argentina, quando não tinha ainda a ponte, tudo que vinha de lá vinha de barcos grandes, né? Traziam feijão, traziam... tudo que era de primeira necessidade. Traziam o arroz, traziam feijão, tudo isso a granel vinha. Tudo vinha de lá de Libres. Levavam muita coisa também. Vinha mais do que ia, porque o que ia daqui era pneu, que levavam... Muita gente dizia até que era contrabando, chegava a se falar que era contrabando, mas isso era da própria época [...] (Seu Santos Reis, 63 anos - Uruguaiana, BR).

Como se percebe nestas narrativas, o contrabando é legitimado pelo fato de que representa uma forma de trabalho, realizado por pessoas honestas que buscam através dele o sustento da família.

Já para Pedro Riera, diretor do Liceu Rural de Cerro Pelado (UY), ao contrário das observações feitas pelos narradores acima, o contrabando, exatamente por ser algo tão profundamente enraizado na cultura da fronteira, traz outras implicações, pois modifica a relação trabalho = dinheiro (sustento), gerando, de certa forma, um ethos diferenciado na população da região:

Los contrabandistas son simpaticos, todos los queremos y sabemos quien son. Los que se dedican al contrabando todos saben con mucha claridad. El tema es: tu estás en Rivera y queres ver un partido de fútbol, Nacional y Peñarol. Bueno, tu vás a la línea [de fronteira] comprá cajas de pilas, verdad? Hacias una inversión. Comprava una caja de pilas, te ibas a Montevideo, entregaba la cajas de pilas en los quioscos de la principal, 18 de Julio, y en media hora vendias todo. Y ahí le quitabas el pasaje y veías el partido. O cuando tavas estudiando, estudiante de facultad, venir a Rivera era muy dificil, para ver la novia, y como hacias? Venia, comprava cubiertos y revendias los cubiertos allá. Allá te pagavan cuatro veces 
más. Entonces vendias varias cajas de Hercules Inox, no? Vendias allá, todo contento, una cajita de chicle y tava pronto. Y ya le quitabas el pasaje. [seu relato salienta a comicidade da situação] Si tu con 15 años, con 18 años, en lugar de trabajar, de pedir trabajo, de jardinero o podando o pintando... entonces, en vez de hacer todo ese esfuerzo y sudar, tu vas y compras tres cajas y satisfaces tus necesidades basicas, despues te vas para la gran ciudad de Montevideo a ver el fútbol, porque vas te esforzar? Eso crea una conciencia facilitadora en el hombre de la frontera.

Mas existem também os pequenos contrabandos feitos pelas famílias para consumo próprio. Estes são plenamente legitimados pela população fronteiriça e a sua repressão pela polícia, criticada, como se pode verificar no comentário de Dona Yolanda, de Moirones (UY):

Sim, que tá brabo, pra trazerem tá horrible, andam prendendo! As caminhonetinhas, os caminhões, igual prendem. Mas sempre algum escapa, né? Senão nós ia morrer tudo de fome. Se a gente fosse comprar tudo daí do Uruguai, era bravíssimo.

Essas apreensões tinham, por vezes, implicações legais mais sérias. Como naquele momento (anos de 2001/2002) o poder de compra da moeda uruguaia era utilizado no sentido de multiplicar os recursos administrados pelas escolas rurais para compra dos alimentos da merenda escolar, era comum que estes alimentos fossem contrabandeados do Brasil. Numa ocasião em que estava hospedada numa escola rural, vi a diretora esbravejar quando soube que todos os alimentos perecíveis que estavam sendo trazidos para a escola (carne, chorizo, frutas, verduras etc.), comprados no "outro lado", haviam sido confiscados. Ela então, munida da legitimidade social deste procedimento, telefonou imediatamente para a aduana, conversou com o policial, explicou-lhe que, se os alimentos ficassem retidos, as crianças passariam fome, e ele, aceitando sua argumentação, decidiu liberar-lhe o carregamento. Este episódio permite-nos perceber que, por vezes, há conivência dos próprios agentes de controle - polícia, fiscais - na realização do contrabando, de acordo com a "justificativa” deste, isso sem falar no pagamento de propinas (coima, como é chamado em espanhol) que, em muitos casos, também viabiliza a liberação dos produtos contrabandeados.

Na fronteira da Argentina com o Brasil, as relações de comércio foram se modificando ao longo do tempo e diminuindo, como vemos na fala de Dona Maria de Fátima, de Uruguaiana: 
DM - Antigamente até uma roupa a gente trazia de lá - de Libres - uma lã que era maravilhosa, o tecido! E roupas que duravam anos e anos e anos, né? Eles tinham... tudo era bem melhor. Só que hoje não dá mais pra ir lá.

Por outro lado, o esposo de Dona Maria, Seu Santos Reis, comenta sobre o relacionamento que ainda mantém com os vizinhos de Paso de Los Libres: "Eu tenho companheiros que jogam futebol junto comigo que são de lá - de Libres. Eles vêm aos domingos, todos os domingos eles vêm aqui jogar. Então, essa amizade nós mantemos. Se queremos bem, se respeitamos".

\section{Família}

Além de relações comerciais e de contrabando, há muitas outras formas de integração entre as sociedades fronteiriças. Uma das alianças mais fortes neste sentido são certamente aquelas estabelecidas a partir dos laços de parentesco. Casamentos realizados entre indivíduos de países diferentes são usuais, confirmando a tradição de afinidade entre os vizinhos. A existência de famílias bi ou trinacionais, cujos membros manejam distintos idiomas no cotidiano, é algo absolutamente comum na fronteira, e ocorre desde o início do seu processo de povoamento. E a questão da nacionalidade dos indivíduos muitas vezes é resolvida não através de uma restrição, mas de uma ampliação da questão: por que um sujeito seria apenas brasileiro ou uruguaio se ele pode ser ambos? Estes sujeitos com dupla nacionalidade, que não são poucos, possuem inclusive uma alcunha local: são os doble-chapas. Isto ocorre especificamente na fronteira Brasil-Uruguai devido ao fato de que a legislação uruguaia permite atribuição de nacionalidade a todo filho de mãe uruguaia e não impede seu cidadão de possuir outra nacionalidade:

Yo, para ir a todo el Brasil, tengo mis documentos, soy brasileño. Ahí entro en el Uruguay, soy uruguayo. Voy y vengo, transito libremente.Y todo auténtico, el papel de nacimiento hasta... Está todo legal, todo conforme, sólo que no salgas con los dos documentos a la vez y ahí donde se genera algún desastre. [risos] El uruguayo puede tener otra nacionalidad (Pedro Riera, 50 anos - Cerro Pelado, UY).

Em relação à fronteira argentina, embora de acordo com a Constituição daquele país não seja aceito o direito à dupla cidadania, o trânsito de pessoas de um lado ao outro é permanente, e os laços familiares entre brasileiros e argentinos estão presentes neste e em outros espaços. Na prática, portanto, a condição de ser cidadão brasileiro ou cidadão argentino não interfere no cotidiano dos moradores da região. 
Os doble-chapas, alusão aos carros da região que teriam placas duplas, circulam livremente pelos dois territórios nacionais, podendo possuir documentos, trabalhar, estudar e inclusive aposentar-se num ou noutro país. O que frequentemente ocorre, no entanto, e que me foi segredado em diversas ocasiões, é que, entre outras coisas, muitos desses cidadãos aproveitam o privilégio para acumular aposentadorias nos dois países:

O Seu Ari (o antigo capataz da estância) não se recuperou, né? Ele tem problema de rim, tem que fazer hemodiálise três vezes por semana. Eu acho que ele conseguiu se aposentar. No início ele não queria se aposentar, né? E ele, podendo se aposentar por aqui, pelo Uruguai, e por lá, pelo Brasil, podia receber pelos dois lados. Mas acho que agora ele tá aposentado (Seu João, 54 anos - Massoller, UY).

O fato de uma mesma família possuir membros de uma e de outra nacionalidade também pode ser bastante vantajoso em termos legais, como explica Dona Nair, de 69 anos - Cerro Pelado (UY):

DN - Eu vim morar aqui em Cerro Pelado [Uruguai] depois que me casei, e depois nós fomos pra lá. E eu tive dois anos e meio em São Gabriel [Brasil]. Eu tenho uma guria que é gabrielense, a Carmen é gabrielense, a Carmen nasceu lá. E eu roubei dois anos de idade dela pra poder registrar ela aqui, porque ele [seu marido] trabalhava aqui e nós ganhava por vacinação familiar.

Carmen - Eu fui roubada. Diz que sempre é bom...

$\mathrm{DN}-\ldots$ ter um brasileiro na família, né? Pero naquele entonce nós não sabia que sempre era bom pra botar um auto, por um documento... por isso eu registrei ela aqui, a Carmen.

O sentimento de pertencimento à outra nacionalidade aparentemente também não parece ser motivo de conflito. As diferenças são aceitas, toleradas, negociadas, como vemos na fala de Tomazito, de 80 anos - Rivera (UY), em relação à sua avó brasileira:

Era una mujer extraordinaria. Esta mujer, tuviera sido hombre, seria un caudillo, una persona que... Tu sabes que ella vivió hasta los 104 años y jamás habló en castellano, de tan patriota que era. Crió a los hijos, los hijos se educaran en castellano, nunca habló en castellano, siempre en portugués. Y tenia un sentido, un sentido patriótico, cuando tocaban el himno, cuando se hablaba del Brasil... Interesantísimo! 
Estes são apenas alguns exemplos etnográficos selecionados da vasta gama de comentários, realizados durante narrativas mais longas, que seguem pela mesma linha: praticamente todos os interlocutores com os quais tive contato possuem relações de parentesco que atravessam as fronteiras. É interessante perceber, além do conteúdo destas falas, como a própria maneira de expressá-las - através da mescla de idiomas e da performance oral - revela um tal imbricamento de culturas que faz com que estas se pareçam e se confundam, a ponto de comporem, como tenho tentado argumentar, uma só cultura - da fronteira.

\section{Idioma}

A questão do manejo de dois ou mais idiomas, e da sua alternância, é comum à comunidade narrativa desta fronteira e tem relação com o contexto de atuação dos sujeitos, ou seja, sua "comunidade de fala" (Hymes, 1972). Nas fronteiras uruguaia e brasileira, sobretudo entre a população rural, fala-se cotidianamente o "dialeto fronteiriço", comumente chamado de "portunhol”. ${ }^{19}$ Entretanto, como esse dialeto não é legitimado perante as instituições (escolas, bancos, órgãos governamentais), quando a população se dirige a seus membros, vê-se obrigada a trocar de idioma, como nota Seu Ruben, 55 anos, professor, de Rivera (UY):

Pero vas a ver como habla el estanciero cuando llegue Banco de la Republica, cuando va a pedir un préstamo, cuando está hablando con el gerente. Nuestro estanciero que habla el dialecto. Que si, hablamos el dialecto, sí! Incluso funcionarios, por ejemplo, la policía, ellos también te hablan en dialecto, salvo cuando están con sus superiores. [...]Y para nosotros, por ejemplo, el fronterizo, cuando nuestro hijo fue a estudiar, le preguntamos: "Como te encontras?" - “Mirá - dice - yo estoy bien, pero estoy con saudades de ustedes”.Y saudades no tiene traducción.

Mesmo dentro da própria casa alguns indivíduos mais idosos, iletrados, podem utilizar o espanhol quando falam com os netos que frequentam a escola, por exemplo, e o dialeto quando falam entre si, como pude presenciar mais de uma vez. A escola de certa forma representa um "divisor de águas" entre a comunidade, já que as crianças nela são socializadas no idioma nacional, sendo estimuladas a abandonar os dialetos fronteiriços. É comum, entretanto, que o uso do vernáculo se restrinja apenas ao ambiente da instituição e que no lar as crianças voltem a compartilhar as regras de fala utilizadas pela família.

Também na interação comigo era comum que ocorresse a mudança de código que caracteriza essa comunidade de fala: no caso dos narradores uruguaios, eles 
começavam contando suas narrativas em espanhol e, posteriormente, quando se sentiam mais à vontade e percebiam que eu não fazia qualquer cerceamento nesse sentido, passavam para o "portunhol", utilizando somente algumas expressõeschave em espanhol, como entonces, bueno, lejos, empezava etc. Com os contadores brasileiros a mudança era, ao contrário, do português para o "portunhol”.

Por outro lado, frequentemente eu também acabava por compartilhar as regras de fala desses narradores e, quase sem perceber, passava da mesma forma a alternar os dois idiomas em questão ou a utilizar palavras do dialeto fronteiriço.

Esta "contaminação" de idiomas ocorre de forma diferenciada na Argentina. A província de Corrientes tem grande parte de sua população composta de descendentes de indígenas guarani. Com isso, a alternância de idiomas se dá principalmente entre o guarani e o espanhol, sendo que, de forma semelhante ao que ocorre com o "portunhol" na fronteira uruguaia, ali é o guarani que é desprestigiado socialmente. Fui entender esta relação quando comecei a escutar, reiteradas vezes, pedidos de desculpas de um contador argentino que se expressava em guarani:

Pero bueno, no me va a interpretar mal, porque el señor dice que entiende. [refere-se ao senhor que me acompanhava] Bueno, tá. Como Cambá Lacour entiende el guaraní, hablo y así que la señorita también va a ententer... Que no me va a interpretar mal!" (Antolín Zaracho, 86 anos, tropeiro aposentado - Mercedes, AR).

O manejo dos diferentes idiomas, nestes casos, é uma condição de comunicação entre grupos pertencentes às diferentes esferas da sociedade. Assim, um estancieiro falante de espanhol, para adaptar-se ao contexto majoritariamente guarani dos peões, deve comunicar-se nesta língua, como explica Don Jorge, em conversa com Côco Rodriguez, ambos de Paso de Los Libres (AR):

DJ - Una ascendencia que hay en Corrientes también que es muy importante es la ascendencia paraguaya. Acá hubo una época que prácticamente en toda la provincia se hablaba guaraní.

CR - Hasta ahora.

DJ - Vos te vas a unas ciudades, como Mercedes, acá cerca, el guaraní todo el mundo lo sabe, no?

$\mathrm{CR}$-Vos decís: pero ese está burlando de mi, porque te está hablando en guaraní. DJ - Incluso hay programas acá, de radio, que te hablan mitad y mitad, viste? Por ahí te hablan en guaraní y por ahí te hablan en...

CR - Hay mucha gente de campo que escucha... 
DJ - Incluso acá los peones sabían sólo el guaraní, ni siquiera el castellano sabían. Así que el dueño de la estancia tenia que saber guaraní para hablar con los peones (grifo meu).

Durante a pesquisa de campo na cidade de Mercedes, citada na conversa acima, compreendi que o panorama das línguas faladas na região era ainda mais complexo, pois ao conhecer Don Estebán, de 57 anos, descendente de escravos brasileiros que imigraram para a região, ele me contou que em sua família, até a geração de sua mãe, o português também era falado, porém com a intensificação da repressão nas aduanas de fronteira, que impedem o tráfego mais frequente entre os países, o idioma foi se perdendo. Já para os brasileiros que vivem na fronteira com a Argentina, nem sempre o espanhol é bem compreendido, como ouvi diversos interlocutores comentarem.

Por outro lado, o que certamente se mantém, como lembra Seu Ruben, de Rivera (UY), é o idioma comum do comércio, que perpassa toda a zona de fronteira: "Ahí en Libres van uruguayos, brasileños, argentinos, hay de todo. Yo he ido ahí conocer y...Y se entienden prácticamente bien. Hay un idioma común que es: “Te compro, me vendes".

Voltando à fronteira uruguaia, é interessante perceber como o manejo ambíguo dos idiomas se reflete nas relações de identidade e alteridade da população. Assim, os brasileiros da fronteira muitas vezes recebem alcunhas pejorativas que os identificam com os vizinhos uruguaios e argentinos, como comentou Seu Torres, peão campeiro, de Uruguaiana (BR): “Antigamente, quando nós ia pra Porto Alegre, os caras nos chamavam de castelhano. [...] não entendia quase que nada que o cara falava”.

Da mesma forma, os uruguaios que moram na fronteira também são identificados com os vizinhos do "outro lado":

Em Montevideo nos chamam "os brasileiros", né? Nós que semo entreverado porque nós semo uruguayo pero não falemo completamente em uruguayo, né? Em Montevideo dizem “os brasileiros”, porque não entendem quase nós, né? Nós se entendemos, pero em Montevideo a gente já peludeia, já não entendemos bem (Dona Araceli, 60 anos, dona de casa - Moirones, UY).

Tomazito Berruti, de Rivera (UY), também conta que passou pela mesma experiência quando foi estudar em Montevideo: "A nosotros nos llamaban "los brasileros". Todos los otros nos llamaban "los brasileros" a nosotros de Rivera, para que vos vea que la frontera es una cosa distinta (grifo meu)".

Ao contrário de Dona Araceli, no entanto, que passou a vida em Moirones, lo- 
calidade bastante próxima da fronteira com o Brasil, Tomazito morou durante vários anos na capital do país, onde completou seus estudos, daí a diferença nas formas de expressão dos dois: D. Araceli utiliza o "portunhol” (no qual novamente a metáfora "entreverado" aparece, referindo-se à mistura de idiomas), enquanto Tomazito privilegia o espanhol. Percebe-se com estes dois exemplos que as diferentes regras de fala utilizadas podem ser relativas à origem social do narrador (Tomazito é estancieiro, D. Araceli é lavadeira), mas sobretudo ao grau de instrução e à moradia no campo ou na cidade (a frequência de uso e de aceitação do "portunhol" é muito maior no meio rural).

É importante observar ainda que o fato de pertencer a uma comunidade de fala caracterizada como "da fronteira" acaba colocando a população da região, em muitos casos, em posição de inferioridade em relação àquelas situações nas quais os códigos e as regras de fala exigidos são os do idioma standard nacional (Quant, 1994). Embora os membros dessa comunidade de fala - especialmente aqueles oriundos do meio rural - possam enfrentar dificuldades em algumas situações mais formais, nas de contato informal, comuns ao cotidiano fronteiriço, a sua capacidade de compreensão e de manipulação dos diferentes códigos, ao contrário, é fortemente valorizada.

\section{Cotidiano, Trabalho, Educação, Lazer}

Para finalizar a exposição das relações que se estabelecem nesse espaço "intrafronteiriço", é necessário ainda acrescentar que, além do comércio e do parentesco, estas relações estendem-se a outros aspectos da vida cotidiana, de acordo com a fronteira em questão. Entre Uruguai e Brasil, há inúmeras famílias de Rivera que vivem em Livramento, e vice-versa. Muitos uruguaios vivem em Rivera, mas trabalham ou têm negócios no Brasil (em Santana do Livramento, Quaraí, Alegrete etc.). O contrário também ocorre: há vários casos de agrônomos ou veterinários brasileiros que trabalham em estâncias uruguaias. Conheci, por exemplo, uma professora uruguaia que é casada com um brasileiro, eles moram em Livramento, ela, porém, trabalha em Rivera, mas frequenta o Rotary Clube de Livramento (o Rotary de Rivera não permite que as mulheres participem como membros). Também é comum que crianças de Quaraí (BR) estudem em Artigas (UY), devido à melhor qualidade de ensino no Uruguai. Nesta região, apesar de os uruguaios realizarem compras em Quaraí, nos fins-de-semana é a praça central de Artigas que fica repleta de brasileiros. No aspecto "lazer", o mesmo ocorre com Rivera: os brasileiros juntam-se aos uruguaios nos sábados e domingos à tarde para passear e tomar mate na avenida principal da cidade, a Sarandi. Na praça de Rivera também não é estranho se deparar com uma roda de capoeira.

Há, no entanto, uma ocasião em que os sentimentos nacionalistas se acirram, 
opondo-se radicalmente; por incrível que pareça, isto não ocorre por discordâncias no campo da política ou da economia, mas no campo, literalmente, do futebol: "Nosotros estamos hermanados desde niños. La única rivalidad es el fútbol” (Pedro Riera - Rivera, UY). ${ }^{20}$

Sobre o tema há inúmeras narrativas que percorrem a fronteira, sempre contadas em tom jocoso, mas durante a pesquisa de campo pude perceber como esta rivalidade é levada a sério pela população: em ocasiões de partidas entre as seleções do Uruguai e do Brasil, o policiamento é intensificado na avenida que divide Livramento de Rivera e as fronteiras são praticamente fechadas à circulação, só voltando ao normal depois do jogo, e isso conforme o resultado.

$\mathrm{Na}$ zona rural é fácil encontrar peões de várias nacionalidades que alternam trabalho em estâncias dos três países. Nas profissões mais sazonais, como domadores, tosquiadores, alambradores (construtores de cercas) e os antigos tropeiros, o trabalho indiscriminado nos países vizinhos é ainda mais frequente. Na fronteira entre Argentina e Brasil, apesar do menor trânsito da população, há vários habitantes de Uruguaiana cursando o ensino superior em Paso de Los Libres, especialmente pelo fato de que lá o ensino é público, enquanto na cidade brasileira existiam (naquele momento) somente faculdades privadas.

Também na questão do lazer os jovens são os que mais vão em busca de alternativas, frequentando danceterias e bares de ambos os lados. Até mesmo o trânsito de Uruguaiana, segundo me disseram, teve de se adaptar aos motoristas do país vizinho, caracterizando-se como um dos mais perigosos da fronteira, já que "cada um obedece à sua própria lei”. Quanto às relações empregatícias, pude constatar que na fronteira argentina há realmente uma menor frequência de brasileiros. Estes estão presentes, sobretudo, na área de produção e distribuição agropecuária, especialmente nas lavouras de arroz, com alguns proprietários de terras na região que, entretanto, moram em Uruguaiana.

\section{Considerações finais}

Ao longo dessas páginas, procurei demonstrar que as narrativas orais e seus narradores exercem um importante papel na tão propagada "integração" dos povos da fronteira. Esta forma de expressão simbólica possibilita à população organizar, compreender, transmitir e transformar a experiência paradoxal, e por vezes conflituosa, de ser igual e de ser "outro" que caracteriza e adjetiva essa região - "fronteiriça".

Os diversos discursos mencionados ao longo do texto corroboram a ideia que defendo de que a fronteira, mais do que uma linha divisória, pode ser vista como uma faixa, uma região, no sentido de um espaço socialmente definido onde são compartilhados códigos culturais. 
A ideia de que há um "espaço fronteiriço" onde coexistem sujeitos, tradições, histórias, economias, idiomas e, sobretudo, narrativas deu sustentação à minha pesquisa e alimentou minha argumentação a respeito do que passei a chamar de "cultura da fronteira". Ao longo da pesquisa etnográfica, pude observar que havia relacionamentos "intrafronteiriços" que geravam dinâmicas identitárias específicas do viver na fronteira. O sentimento de identidade fronteiriça não ocorre necessariamente no compartilhar dos cruzamentos da "linha" ou da ponte mas, ao contrário, ocorre na vivência desse espaço ambíguo que se constitui por tais atravessamentos. Ou seja, não é "entre" fronteiras que os relacionamentos e as trocas em diversos níveis ocorrem, mas “intra”, dentro do espaço fronteiriço. Acredito, nesse sentido, que a análise das diversas performances da oralidade pode contribuir substancialmente na compreensão de como a população local se autoidentifica a partir desta base comum: a experiência de viver na fronteira.

Difundindo um imaginário comum, a circulação das narrativas orais produz uma sensação de identidade entre os habitantes desta "faixa de fronteira" entre os três países. A intensidade de contato da população fronteiriça, nos mais variados níveis, constrói os múltiplos caminhos que as narrativas orais e suas performances dispõem para circular entre e, sobretudo, "intra" fronteiras. As narrativas constituem, portanto, um importante elo que une as experiências de contadores e a audiência numa mesma comunidade narrativa, fazendo com que a cultura da região, com seus sotaques e gestos, seja compartilhada e circule também entre as fronteiras.

Recebido em 15 de outubro de 2009

Aprovado em 7 de agosto de 2010

Luciana Hartmann é doutora em Antropologia pela Universidade Federal de Santa Catarina (2004). Atualmente é professora do Departamento de Artes Cênicas e do Programa de Pós-Graduação em Arte da UnB, atuando na linha de Antropologia da Performance. Realiza pesquisa de campo na fronteira entre Argentina, Brasil e Uruguai desde 1997. Email: <luhartm@yahoo.com.br> 


\section{Notas}

1. Gustavo Lins Ribeiro (1993: 9), em texto que toma por base sua pesquisa realizada na fronteira entre a Argentina e o Paraguai, oferece uma resposta à questão: "as culturas das fronteiras são cenários propícios também para encontrar as fronteiras da cultura [...]".

2. Utilizo narrativa no sentido atribuído por Langdon (1994:54) de "contar um acontecimento em uma sequência estruturada, a qual, na sua forma mais simples, possui uma introdução, um desenvolvimento e uma conclusão". Quanto ao discurso, pretendo assumir uma conotação mais ampla, na linha de Greimas e Courtés (1989:127), que o definem como “tudo aquilo que é colocado pela enunciação, pois “enunciação' é a colocação em discurso".

3. Realizo pesquisa de campo na região desde 1997. A pesquisa específica, que deu origem à minha tese de doutorado, contendo uma primeira versão deste artigo, foi realizada entre os meses de abril de 2002 e maio de 2003. O trabalho etnográfico estendeu-se pela faixa de fronteira que compreende as cidades (e, sobretudo, suas respectivas zonas rurais) de Paso de Los Libres, La Cruz e Mercedes (Argentina); Santana do Livramento, Quaraí, Caçapava do Sul, Alegrete, Barra do Quaraí, Uruguaiana (Brasil); e Massoller, Minas de Corrales, Rivera, Artigas, Bella Unión, Vichadero (Uruguai).

4. É importante ressaltar que, embora as narrativas e os discursos que compõem este artigo tenham sido selecionados justamente pela referência específica à problemática fronteiriça, a "fronteira" é tema recorrente da população em suas múltiplas formas de oralidade cotidiana. As características e as especificidades das narrativas orais que circulam na região já foram objeto de outros trabalhos (Hartmann, 2004, 2005, 2006) e, por este motivo, não serão enfocadas aqui.

5. A “Tese de Turner” (Turner Thesis) é detalhada por Velho (1976) e profundamente debatida por Klein (1997).

6. Mesquita (1994:69), procurando distinguir o conceito de fronteiras em geografia política, coloca: 'fronteira vem da noção de in front: 'em frente' como a ponta de lança da civilização. Limite vem de bounds - 'limites', 'fins', implicando limites territoriais. Fronteira é por isso orientada para fora (exterior) e limite é uma linha de separação definida; a fronteira é uma zona de contato”.

7. Para Donnan e Wilson (1999:10), os problemas de definição dos limites entre culturas no mundo pós-moderno levaram os grupos sociais a ser qualificados por prefixos, como "pós", "trans", "supra”, "intra” e "meta”. Estas são, para eles, tentativas de criar novos vocabulários capazes de articular molduras conceituais e analíticas para o estudo de povos que não estão mais cercados por limites de nação ou Estado como em outro momento estiveram.

8. Na região pesquisada, a relação entre a fronteira e suas narrativas é tão forte que motiva o comentário de Gaúcho Barreto, 62 anos, dono de bolicho (armazém) - Santana do Livramento (BR): “Aqui nessa fronteira, onde tu vê beira de linha, tu vai ver cuento...” e a frase acaba dando título à minha tese de doutorado (Hartmann, 2004).

9. Bleil de Souza (1994:86) retoma as descrições desta mesma região feitas por J. Resende Silva, encarregado de fiscalizar a fronteira do RS entre os anos de 1919 e 1921: "[ele] fez ainda 
referência às chamadas 'habitações internacionais' que existiam em grande número até nos próprios limites urbanos das duas cidades: casas construídas, parte no território brasileiro e parte no uruguaio, como uma mencionada que tem 'a sala e a alcova no Brasil, e as demais dependências no Uruguai'".

10. Para o historiador Manoelito de Ornellas (apud Rocca, 2002:74), existiu uma "interpenetração social, facilitada pelo Pampa, como território comum a três países”.

11. Noção-chave para a compreensão da realidade local, “conflito” não será aqui tomado simplesmente como uma divergência dos processos sociais normais, mas, ao contrário, envolve formas complexas que participam na própria constituição da vida social (Briggs, 1996:13).

12. Exploro a constituição dos contadores de causos como sujeitos através das relações de conflito em Hartmann (2007).

13. Comentando uma pesquisa realizada sobre identidade fronteiriça na mesma zona aqui enfocada, Cardoso de Oliveira (2000:328) assinala que, a despeito das identidades nacionais serem devidamente respeitadas, cria-se uma identidade fronteiriça, uma identidade secundária, articuladora das identidades nacionais.

14. Estas cidades podem ser caracterizadas como “cidades-gêmeas”. Sobre este tema, vale aqui trazer alguns aportes: para Pébayle (1994:15), da forma particular com que as relações comerciais se estabelecem na fronteira resulta uma organização espacial específica, que ele chama de "hierarquias urbanas simétricas", que apareceriam sob a forma de duplas urbanas (também chamadas de cidades-gêmeas) "cujas funções comerciais são a resultante direta do fenômeno de compensação, mais ou menos visível, entre economias regionais e nacionais diferentes". Em Quant (1994:94) esta relação também aparece: "Es normal que a lo largo de las fronteras se establezcan ciudades gemelas, surgidas naturalmente por intereses comerciales o como respuesta de un país a su política de fronteras para neutralizar la presencia y posible expansionismo de los vecinos extranjeros”.

15. Müller (2002:228) faz uma observação semelhante a esse respeito: "Tal relacionamento, onde as diferenças na legislação de cada país são ressaltadas, não deixa de demonstrar que há uma interação permanente entre as partes envolvidas e, na verdade, o que mais contribui para os desacertos são as decisões tomadas em nível nacional por governos centrais, que ignoram a situação peculiar dos espaços fronteiriços”.

16. Numa cidade como Rivera, com cerca de 70 mil habitantes, não era difícil que, entre os mais de 20 presos, houvesse algum amigo, parente ou conhecido de meus interlocutores.

17. Segundo Albornoz (2000:128), “A grande verdade é que os frigoríficos na região platina eram um 'excelente negócio' enquanto foi possível manter o monopólio, enquanto os sindicatos eram fracos, e o preço da mão de obra era muito baixo".

18. A pouca problematização e mesmo a falta de inserção das questões de gênero são apontadas por Jelin (2000) como uma das mais graves lacunas nos estudos sobre fronteira.

19. De acordo com Carvalho (2010), "É devido à exposição constante aos dialetos monolíngues circundantes que frequentemente os bilíngues acreditam que falam uma variedade linguística inferior ao português brasileiro e ao espanhol do sul do país [Uruguai]. Essa insegurança linguística, comum em sociedades bilíngues, leva os falantes de português uruguaio a 
menosprezarem esse idioma, conferindo-lhe status de uma variedade híbrida, um 'portunhol'”. Percebo, neste sentido, que a expressão "dialeto fronteiriço" é utilizada em substituição ao "portunhol” pela população local (da fronteira entre Brasil e Uruguai mais especificamente) como uma estratégia de legitimação dos idiomas manejados em sua fala cotidiana.

20. A esse respeito, Osterman (2002:211-212), comentarista esportivo de Porto Alegre, observa: “Os únicos estremecimentos dessa placidez de campo, cercado, árvore e céu são jogos de Copa do Mundo ou equivalentes esportivos, mas só aqueles que jogam com os valores universais dos países afronteirados, o Brasil, o Uruguai, a Argentina. Desaparece, então, a interioridade das províncias lindeiras, reassumem-se na nacionalidade e num breve, às vezes consistente, estado de beligerância. Há provocações, intimidações, conflitos pessoais e familiares de tal grandeza iminente que se fecha a fronteira, antes naturalmente transitável, entre Santana e Rivera, por exemplo, quebram-se coisas, xingam-se”. 


\section{Referências Bibliográficas}

AGUIAR, Flávio Wolf de. 2002. "A América Latina não Existe”. In: M. H. Martins (org.). Fronteiras Culturais: Brasil, Uruguai, Argentina. Porto Alegre: Ateliê Editorial.

ALBORNOZ, Vera do Prado Lima. 2000. Armour: uma aposta no Pampa. Santana do Livramento: ed. da autora.

BASTIDE, Roger. 1980. "O Pampa e o Cavalo”. In: Brasil: Terra de Contrastes. 10. ed. Tradução de Maria Isaura Pereira de Queiroz. São Paulo/Rio de Janeiro: Difel.

BLEIL DE SOUZA, Suzana. 1994. "A Fronteira do Sul: trocas e núcleos urbanos - uma aproximação histórica”. In: A.C. Lehnen, I.R. Castello \& N.O. Schäffer (orgs.). Fronteiras no Mercosul. Porto Alegre: Ed. da Universidade/UFRGS \& Pref. Municipal de Uruguaiana.

BRIGGS, Charles. 1985. “The Pragmatics of Proverb Performances in New Mexican Spanish”. American Anthropologist, 87(4):793-810

1996. “Introduction”. In: C. Briggs (ed.). Disorderly Discourse - narrative, conflict and inequality. New York/Oxford: Oxford University Press.

CARDOSO DE OLIVEIRA, Roberto. 2000. "Epílogo 1: Fronteras, naciones e identidades". In: A. Grimson (org.). Fronteras, naciones e identidades - la periferia como centro. Buenos Aires: Ciccus/La Crujía.

CARVALHO, Ana Maria. 2010. "Contribuições da sociolinguística ao ensino do português em comunidades bilíngues do norte do Uruguai”. Pro-Posições, 21(3):45-65.

DONNAN, Hastings \& Thomas M. WILSON. 1999. Borders - frontiers of identity, nation and state. Oxford and New York: Berg.

FONSECA, Claudia. 1993. "Apresentação". In: C. Fonseca (org.). Fronteiras da Cultura: horizontes e territórios da antropologia na América Latina. Porto Alegre: Ed. Universidade/UFRGS.

GIDDENS, Anthony. 1994. “The National Power-Container”. In: J. Hutchinson \& A.D. Smith (eds.). Nationalism. Oxford/New York: Oxford University Press.

GREIMAS, Algirdas Julius \& COURTES, Joseph. 1989. Dicionário de Semiótica. Tradução: Alceu Dias Lima et alii. São Paulo: Cultrix.

GRIMSON, Alejandro. 2000. "Introducción - ¿Fronteras Políticas versus fronteiras culturales?”. In: A. Grimson (org.). Fronteras, naciones e identidades - la periferia como centro. Buenos Aires: Ciccus/La Crujía.

HARTMANN, Luciana. 2004. "Aqui nessa fronteira onde tu vê beira de linha tu vai ver cuento"tradições orais na fronteira entre Argentina, Brasil e Uruguai. Tese de Doutorado em Antropologia Social, UFSC.

2005. "Performance e experiência nas narrativas orais da fronteira entre Argentina, Brasil e Uruguai”. Horizontes Antropológicos, 24:125-153. 
. 2006. "Narrativas orais, uma porta de entrada para a cultura da fronteira entre Argentina, Brasil e Uruguai”. In: L. Chiappini \& M.H. Martins (orgs.). Cone Sul: Fluxos, Representações e Percepções. São Paulo: HUCITEC. pp. 167-190.

. 2007. “As Narrativas pessoais e a constituição dos contadores de causos como sujeitos”. In: F. Fischman \& L. Hartmann (orgs.). Donos da Palavra: autoria, performance e experiência em narrativas orais na América do Sul. Santa Maria: Editora da UFSM. pp. 95-229.

HYMES, Dell. 1972. "Models of the interaction of language and social life". In: D. Hymes \& J. J. Gumperz (orgs.). Directions on Sociolinguistics. New York: Holt, Rinehart and Winston.

JELIN, Elizabeth. 2000. “Epílogo II - Fronteras, nacionales, género - un comentario”. In: A. Grimson (org.). Fronteras, naciones e identidades - la periferia como centro. Buenos Aires: Ciccus/ La Crujía.

KLEIN, Kerwin Lee. 1997. Frontiers of Historical Imagination - narrating the european conquest of Native America, 1890-1990. Berkeley/Los Angeles/London: University of California Press.

LABALLE, Alejandro González. 1996. Linhas e Encruzilhadas, espaço social em um ponto da fronteira Brasil-Argentina. Dissertação de Mestrado em Antropologia Social, UFSC.

LANGDON, E. Jean. 1994. A Negociação do Oculto: Xamanismo, Família e Medicina entre os Siona no Contexto Pluri-Étnico. Trabalho apresentado para o Concurso de Professor Titular na UFSC. LEENHARDT, Jacques. 2001. “A Invocação do Terceiro Espaço”. Revista Cult, IV(45): 18-21. . 2002. "Fronteiras, Fronteiras Culturais e Globalização”. In: M.H. Martins (org.). Fronteiras Culturais - Brasil, Uruguai, Argentina. Porto Alegre: Ateliê Editorial.

MARTINS, José de Souza. 1997. Fronteira: a degradação do outro nos confins do humano. São Paulo: Hucitec.

MARTINS, Maria Helena (org.). 2002. Fronteiras Culturais - Brasil, Uruguai, Argentina. Porto Alegre: Ateliê Editorial.

MESQUITA, Zilá. 1994. "Procura-se o Coração dos Limites”. In: A.C. Lehnen, I.R. Castello \& N.O. Schäffer (orgs.). Fronteiras no Mercosul. Porto Alegre: Ed. da Universidade/UFRGS \& Pref. Municipal de Uruguaiana.

MÜLLER, Karla Maria. 2002. "Práticas Comunicacionais em Espaços de Fronteira: os casos do Brasil-Argentina e Brasil-Uruguai”. In: M.H. Martins (org.). Fronteiras Culturais - Brasil, Uruguai, Argentina. Porto Alegre: Ateliê Editorial.

PÉBAYLE, Raymond. 1994. “As Regiões Fronteiriças e o Projeto de Integração do Mercosul”. In: A.C. Lehnen, I.R. Castello \& N.O. Schäffer (orgs.). Fronteiras no Mercosul. Porto Alegre: Ed. da Universidade/UFRGS \& Pref. Municipal de Uruguaiana.

QUANT, Inês Abadia de. 1994. "Lengua y Cultura en Áreas de Frontera del Mercosur - problemática y propuestas”. In: A.C. Lehnen, I.R. Castello \& N.O. Schäffer (orgs.). Fronteiras no Mercosul. Porto Alegre: Ed. da Universidade/UFRGS \& Pref. Municipal de Uruguaiana. 
RIBEIRO, Gustavo Lins. 1993. "Introdução". In: C. Fonseca (org.). Fronteiras da Cultura: horizontes e territórios da antropologia na América Latina. Porto Alegre: Ed. Universidade/UFRGS. pp. 9-21.

VELHO, Otávio Guilherme. 1972. Frentes de Expansão e estrutura agrária: estudo de penetração numa área da Transamazônica. Rio de Janeiro: Zahar.

. 1976. Capitalismo Autoritário e Campesinato: um estudo comparativo da fronteira em movimento. São Paulo/Rio de Janeiro: Difel. 


\section{Resumo}

Este artigo apresenta a região fronteiriça de Brasil, Argentina e Uruguai através dos discursos da populaçãolocal, argumentando no sentido de que a circulação de narrativas orais se mostra como um dos principais elementos constituidores desta que se configura como uma "cultura da fronteira". O texto está dividido em três partes que procuram cruzar teoria e etnografia. A primeira busca uma aproximação com o conceito de fronteira; a segunda expõe, através de um panorama "macro", o perfil da zona pesquisada, com uma descrição dos principais pontos de convergência entre os três países; e a terceira demonstra, através de um panorama "micro", calcado na etnografia, as relações pessoais - ou "intrafronteiriças" - de comércio, família, idioma, trabalho e lazer. A ideia que permeia o texto é a de que importam menos os limites e as identidades nacionais dos países em questão e mais os sujeitos e as dinâmicas identitárias que são articuladas enquanto eles transitam pelas fronteiras, carregando consigo experiências e narrativas.

Palavras chave: narrativas orais, performance, fronteiras

\section{Abstract}

This article presents the border region of Brazil, Argentina and Uruguay through the narratives of local people. It is suggested that the circulation of oral narratives is one of the main elements that constitute a "border culture". The article is divided into three parts which aim to combine theory and ethnography. The first part examines the concept of border; the second part shows, through a "macro" panorama, the profile of the research area, with a description of the main converging points of the three countries; and the third part demonstrates, through a "micro" panorama, based on ethnography, the personal - or the intraborderline - relationships of commerce, family, language, labor and leisure. The idea which permeates the article is that the national limits and identities of the countries in question mean less than the persons and the identity dynamics that are articulated while they cross the borders, carrying with them experiences and narratives.

Keywords: oral narratives, performance, borders 